\title{
Deteç̧ão da infecção pelo vírus da artrite-encefalite caprina: imunodifusão em ágar e reação em cadeia da polimerase com "primers" degenerados
}

\author{
[Detection of caprine arthritis-encephalitis virus infection: agar gel immunodiffusion \\ and polymerase chain reaction with degenerated primers]
}

\author{
J.K. Rutkoski ${ }^{1}$, R. Werenicz ${ }^{2}$, D. Reischak ${ }^{3}$, A.C. Wendelstein $^{3}$, V. Moojen ${ }^{3}$, A.P. Ravazzolo ${ }^{3 *}$ \\ ${ }^{1}$ Bolsista PIBIC/CNPq, graduanda de Medicina Veterinária \\ ${ }^{2}$ Graduanda de Medicina Veterinária, Faculdade de Veterinária da UFRGS \\ ${ }^{3}$ Faculdade de Veterinária da UFRGS \\ Caixa Postal 15005 \\ 91501-970 - Porto Alegre, RS
}

Recebido para publicação em 29 de agosto de 2000

Recebido para publicação, após modificações, em 17 de abril de 2001

*Autor para correspondência

E-mail: anapr@dna.cbiot.ufrgs.br

Recursos financeiros: CNPq (bolsas), FAPERGS (processo 96/0322.4), PRONEX em Virologia Veterinária (FINEP 215/96)

\section{RESUMO}

O objetivo deste trabalho foi analisar amostras de soro e de células sangüíneas de caprinos para detecção de anticorpos e DNA proviral do vírus da artrite-encefalite caprina (CAEV), respectivamente. Utilizou-se a técnica de imunodifusão em ágar (AGID) e a reação em cadeia da polimerase (PCR) com "primers" degenerados. Foram analisadas amostras de diferentes procedências: 39 de Mato Grosso do Sul (MS), 19 de São Paulo (SP) e 22 do Ceará (CE), dessas últimas, 12 oriundas de animais importados do Canadá. Os resultados de AGID e PCR foram discordantes, pois o primeiro permitiu a detecção de 25 animais soropositivos, enquanto a PCR detectou DNA proviral de CAEV em 16 amostras. Pela PCR foi possível identificar animais infectados cujos testes sorológicos foram negativos pelo AGID: oito amostras do MS e um do CE. São discutidos diferentes aspectos que poderiam estar envolvidos na discordância dos resultados.

Palavras-chave: Vírus da artrite-encefalite caprina, CAEV, PCR, “primers” degenerados, AGID

\begin{abstract}
The purpose of this work was to analyse serum and blood cells from caprine origin to detect antibody and proviral DNA of caprine arthritis encephalitis virus (CAEV), respectively. Agar gel immunodiffusion (AGID) and polymerase chain reaction (PCR) with degenerated primers were used. Samples of different geographical regions were analysed: 39 from Mato Grosso do Sul (MS), 19 from São Paulo (SP), 22 from Ceará (CE) including 10 from Canada (imported animals), providing a total of 80 samples. The results obtained by AGID and PCR were discordants, as 25 samples were detected as seropositive, while 16 infected animals were detected by PCR. On the other hand, PCR allowed the identification of infected animals that did not have detectable antibodies by AGID: eight samples from MS and one from CE. Different aspects related to these discordant results are discussed.
\end{abstract}

Keywords: Caprine arthritis-encephalitis virus, CAEV, PCR, degenerated primers, AGID 


\section{INTRODUÇ̃̃O}

O vírus da artrite-encefalite caprina (CAEV) é um lentivírus pertencente à família Retroviridae. Foi inicialmente descrito por Cork et al. (1974) como agente causal de encefalite em caprinos jovens, sendo identificado como um retrovírus por Crawford et al. (1980) em animais adultos com artrite crônica. Além de manifestações clínicas, a infecção está associada à mastite (Kennedy-Stoskopf et al., 1985) e à pneumonia intersticial (Narayan et al., 1997). As quatro formas de apresentação da doença são igualmente observadas em ovinos infectados pelo lentivírus Maedi-Visna (MVV) (Narayan et al., 1997). Devido às semellhanças observadas entre os dois vírus, e à possibilidade de infecção cruzada entre ovinos e caprinos, foram denominados lentivírus de pequenos ruminantes (SRLV) (Dickson \& Ellis, 1989; Joag et al., 1996). A infecção por SRLV foi detectada em diversos países da Europa e das Américas (Adams et al., 1984; Narayan \& Clemens, 1989), inclusive no Brasil (Moojen et al., 1986; Hötzel et al., 1993; Castro et al., 1999).

Os lentivírus são assim denominados por ocasionarem doenças de evolução lenta e progressiva, com longo período de incubação. As células alvo são os monócitos e macrófagos e a expressão viral está associada à maturação delas (Gendelman et al., 1986). Há infiltração de leucócitos mononucleares nos órgãos e tecidos alvo atingidos (Joag et al., 1996) e a secreção de citocinas pode estar envolvida na patogenia (Lechner et al., 1997; Legastelois et al., 1997).

O CAEV apresenta semelhanças genômicas e antigênicas com o lentivírus ovino, o que possibilita a utilização de antígenos oriundos de MVV para o diagnóstico sorológico da infecção pelo lentivírus caprino (Gogolewski et al., 1985). Da mesma forma, é possível selecionar "primers" com a capacidade de detecção de ambos os vírus (Zanoni et al., 1992).

O diagnóstico laboratorial pode ser realizado por meio da deteç̧ão de anticorpos (Ac) no soro, isolamento viral ou detecção do DNA proviral pela reação em cadeia da polimerase (PCR). Os principais testes sorológicos empregados para detecção da infecção pelo lentivírus caprino são a imunodifusão em ágar (AGID), ELISA e "Western Blot". No Brasil, utiliza-se principalmente o AGID, geralmente com antígenos importados (Cunha \& Nascimento, 1995). Testes mais sensíveis que o AGID, como o ELISA e "Western Blot" são utilizados em países europeus que possuem programas de erradicação ou de controle da infecção com o estabelecimento de propriedades livres. Embora apresentem maior sensibilidade, esses testes podem não ser definitivos na eliminação de todos os animais infectados. Alguns animais podem apresentar soroconversão tardia (Rimstad et al., 1993), o que permitiria a disseminação do vírus no rebanho. Nesses casos, a técnica de PCR poderia ser indicada para a detecção do DNA proviral. A fim de que a PCR possa permitir a detecção de diferentes amostras virais, os "primers" utilizados devem reconhecer diferentes genomas provirais. Uma das maneiras de otimizar esse reconhecimento é a utilização de "primers" degenerados, desenhados a partir do alinhamento de seqüências nucleotídicas virais. Cada solução de "primers" utilizados na PCR é constituída por uma mistura de "primers", cujas sequiências variam de acordo com as variações observadas nas diferentes sequiências virais alinhadas.

O objetivo deste trabalho foi avaliar a utilização de um teste sorológico, AGID, e um teste de detecção do DNA proviral nas células sangüíneas a fim de comprovar a infecção pelo CAEV.

\section{MATERIAL E MÉTODOS}

As amostras de sangue com anticoagulante (heparina) e de soro foram obtidas no Laboratório de Virologia Clínica da Faculdade de Veterinária da UFRGS e junto à Faculdade de Medicina Veterinária e Zootecnia da UNESP, Botucatu durante o ano de 1998. O total de 80 amostras de caprinos foi encaminhado ao Laboratório de Virologia Clínica da Faculdade de Veterinária da UFRGS para diagnóstico sorológico e PCR para detecção da infecção pelo CAEV. As amostras eram provenientes de 
três Estados: 39 do Mato Grosso do Sul (MS), 19 de São Paulo (SP) e 22 do Ceará (CE), sendo que deste último, 12 amostras eram de animais importados do Canadá (CA). As amostras de MS eram oriundas de uma propriedade com programa de erradicação de CAEV em andamento, onde animais soropositivos no teste de AGID haviam sido detectados e eliminados anteriormente. As outras amostras foram enviadas para simples controle (CA) ou por existirem suspeitas de infecção pelo CAEV (SP e CE).

O teste de AGID foi realizado com o CAPRICLEAR 300 TEST KIT (Veterinary Laboratories Agency, New Haw, Addlestone, Surrey KT15 3NB, United Kingdom), que utiliza antígeno do vírus Maedi-Visna, soro ovino positivo para a gp135 (proteína do envelope viral) e soro caprino positivo para a p28 (proteína do capsídeo). Após disposição dos soros suspeitos, dos controles positivos e do antígeno nos orifícios respectivos, a placa de imunodifusão foi incubada à temperatura ambiente, ao abrigo da luz, por 48h, quando foi realizada a leitura. A presença de uma linha de precipitação com identidade frente aos controles positivos era o indicativo da presença de Ac nos soros em teste. A presença de uma linha de fraca intensidade, impossibilitando a identificação de uma linha similar aos controles positivos, levou à classificação do soro como suspeito. As amostras foram inicialmente testadas com o controle positivo para gp135 e, em caso de soro suspeito ou negativo, um novo teste foi realizado com o controle positivo para p28 (Adams \& Gorham, 1986).

A extração de DNA foi realizada a partir do sangue com anticoagulante obtido de todos os animais testados pelo AGID, utilizando-se DNAzol (GIBCO). Um ml de sangue foi submetido à centrifugação em microtubo, a 3.000rpm (microcentrífuga Eppendorf 5415C) por seis minutos, com a finalidade de separar leucócitos. Duzentos microlitros da interface foram aspirados e submetidos a três lavagens com $1 \mathrm{ml} \mathrm{de}$ TE (Tris.HCl $10 \mathrm{mM}$, EDTA $1 \mathrm{mM}, \mathrm{pH}$ 8) por centrifugação a 10.000rpm por cinco minutos entre cada lavagem. O sedimento foi então submetido à extração com $500 \mu 1$ de DNAzol, conforme as especificações do fabricante. O DNA obtido foi diluído em 100 microlitros de $\mathrm{NaOH} 8 \mathrm{mM}$ e $5 \mu 1$ da suspensão (400 $500 \mathrm{ng}$ ) foram utilizados na PCR.

A PCR foi realizada conforme descrito anteriormente (A enzima Taq DNA polimerase foi cedida pelo Laboratório CENBIOT Enzimas - Centro de Biotecnologia - UFRGS) (Marchesin et al., 1998), com modificações. As sequiências dos "primers" degenerados específicos para o gene gag, bem como sua posição na sequiência do provírus CAEV-CORK (Saltarelli et al., 1990), são apresentados na Tab. 1. Após a primeira PCR, utilizando-se os "primers" L3 e LRT3, o produto obtido foi submetido a uma segunda reação nas mesmas condições da primeira, mas utilizando-se o par de "primers" L4 e LRT3 e com $2 \mu \mathrm{l}$ do produto da primeira PCR como fita molde ("hemi-nested PCR"). O primer L4 é complementar a uma seqüência interna do produto gerado na primeira PCR. Os produtos obtidos foram analisados em gel de agarose a $2 \%$, corados com brometo de etídeo e visualizados em transiluminador de U.V.

Tabela 1. Seqüências de nucleotídeos dos "primers" degenerados utilizados na PCR, específicos para o gene gag dos lentivírus de pequenos ruminantes, e sua localização no genoma

\begin{tabular}{lcc}
\hline Denominação & \multicolumn{1}{c}{ Seqüência } & Localização* \\
\hline L3 & 5'-GG(A/G)GGGAGAAG(C/T)TGGAA-3' & $962-978$ \\
LRT3 & 5'-ACATGCTTGCAT(C/T)TT(C/T)T-3' & $1582-1566$ \\
L4 & 5'-T(A/G)GC(C/T)ATGATGCCTGG-3' & $1109-1125$ \\
\hline
\end{tabular}

*Segundo a sequiência de nucleotídeos da amostra CAEV-CORK (Saltarelli et al., 1990).

\section{RESULTADOS E DISCUSSÃO}

Este trabalho avaliou o uso de "primers" degenerados para detecção de DNA proviral do CAEV, principalmente em situações nas quais o teste sorológico não permite um diagnóstico conclusivo. A escolha de "primers" degenerados teve como objetivo detectar o maior número possível de amostras, uma vez que eles foram desenhados a partir do alinhamento de cinco sequiências de SRLV disponíveis no Genbank. A confirmação da especificidade dos "primers" foi realizada em trabalho anterior, no qual 
foram amplificados fragmentos a partir de isolados e clone de DNA proviral (Marchesin et al., 1998). Os fragmentos então obtidos foram igualmente submetidos à hibridização - "Southern blot" - com sonda específica (Marchesin, 1997).

Os resultados dos testes sorológicos estão resumidos na Tab. 2. Os soros suspeitos e negativos foram avaliados novamente utilizando-se o soro controle positivo para p28. As 80 amostras foram igualmente avaliadas por PCR, a partir de células sangüíneas.

Tabela 2. Resultados dos testes sorológicos de imunodifusão em ágar (AGID) e das reações em cadeia da polimerase (PCR) para detecção do DNA proviral

\begin{tabular}{|c|c|c|c|}
\hline \multirow{2}{*}{$\begin{array}{l}\text { Soros } \\
\left(\text { procedência/total) }{ }^{\mathbf{a}}\right.\end{array}$} & \multicolumn{2}{|c|}{ AGID } & \multirow{2}{*}{$\begin{array}{c}\text { PCR } \\
\text { (positivos/total) }\end{array}$} \\
\hline & $\begin{array}{c}\text { gp } 135 \\
\text { (positivos/suspeitos) }\end{array}$ & $\begin{array}{c}\mathrm{p} 28 \\
\text { (positivos/testados) }\end{array}$ & \\
\hline MS / 39 & $0 / 35$ & $0 / 39$ & $8 / 39$ \\
\hline SP / 19 & $16 / 3$ & $2 / 3$ & $5 / 19$ \\
\hline $\mathrm{CA} / 12$ & $4 / 4$ & $1 / 8$ & $0 / 12$ \\
\hline $\mathrm{CE} / 10$ & $0 / 1$ & $2 / 10$ & $3 / 10$ \\
\hline
\end{tabular}

${ }^{\mathrm{a}} \mathrm{MS}$ = Mato Grosso do Sul; SP = São Paulo; CA = Canadá; CE = Ceará

As amostras provenientes do Mato Grosso do Sul faziam parte de um programa de estabelecimento de propriedade livre da infecção pelo CAEV, onde medidas de controle estavam sendo aplicadas. Os animais com sorologia positiva confirmada pelo AGID haviam sido descartados anteriormente. Assim, os testes sorológicos, conforme o esperado, resultaram em 35 amostras suspeitas e 4 negativas das 39 analisadas. No segundo teste, com soro controle anti-p28, todos as amostras de soro foram negativas. Todas as amostras foram submetidas à PCR, e a partir de oito delas foram amplificados fragmentos do tamanho esperado. Demonstrou-se, neste caso, que a PCR detectou animais infectados que não apresentaram resultado conclusivo no teste de AGID.

Resultados diferentes foram observados na análise das amostras provenientes de São Paulo. Em 18 das 19 amostras foi detectada a presença de Ac utilizando-se o teste de AGID, embora o DNA proviral tenha sido detectado em apenas 5 das 19 amostras analisadas. Dessas cinco, apenas uma correspondia a uma amostra suspeita no teste de AGID sendo as outras soropositivas. A discordância entre os resultados poderia ser explicada por: a) o número de cópias de DNA proviral integrado ao genoma das células sangüíneas era pequeno e b) os "primers" não foram capazes de detectar variantes virais. Considerando-se que os animais apresentaram sorologia positiva para o CAEV quando avaliados pelo AGID, um teste considerado de baixa sensibilidade, há possibilidade de que a carga viral seja baixa em função de altos títulos de Ac presentes. Isto explicaria um número pequeno de células contendo o provírus, diminuindo a possibilidade de detecção na PCR. Esse fato já foi demonstrado para outros lentivírus, como o vírus da anemia infecciosa eqüina (EIAV) e o vírus da imunodeficiência humana (HIV) (Oaks et al., 1998). Além disso, deve-se considerar que, diferente do que ocorre para os lentivírus indutores de imunodeficiência, como o vírus da imunodeficiência felina (FIV), o CAEV não infecta linfócitos e sim monócitos (Gendelman et al., 1985), que constituem apenas 10\% dos leucócitos do sangue periférico e somente nessas células seria detectado o provírus integrado. Com relação à segunda hipótese (b), Turelli et al. (1997) sugerem que o número de variantes virais ou "quasispécies" em animais infectados pelo CAEV é elevado, conforme já demonstrado para HIV. Duas abordagens complementares poderiam esclarecer esses resultados: o uso de outros "primers" em regiões mais conservadas, como o gene pol por exemplo (Leroux et al., 1995), e a utilização de "Southern blot", o que aumentaria a sensibilidade de detecção dos produtos de PCR que não tivessem sido visualizados em gel corado com brometo de etídeo.

Nas amostras provenientes de animais importados do Canadá os resultados de PCR foram negativos, pois os fragmentos amplificados não correspondiam ao esperado, embora em cinco das 12 amostras tenha sido 
detectada a presença de Ac no soro. A situação é similar à ocorrida com as amostras provenientes de São Paulo e as justificativas para tais resultados também poderiam ser as mesmas citadas acima.

Das 10 amostras do Ceará, duas apresentaram Ac para CAEV e em três foi detectada a presença do provírus. Das três amostras positivas por PCR, duas tiveram resultado suspeito no AGID. Igualmente, como observado nas amostras provenientes de MS, o número de animais infectados detectados foi maior pela PCR do que pelo AGID.

Considerando-se o total de amostras avaliadas, o teste de AGID detectou maior número de animais infectados pelo CAEV, 25/80, quando comparado com a PCR, 16/80. Analisando amostras oriundas de propriedades com programa de erradicação em andamento (MS), a PCR foi capaz de detectar animais soronegativos.

Conclui-se que a utilização de PCR como método de diagnóstico do CAEV deve ser analisada com cautela, em situações específicas. Na avaliação inicial de um rebanho deve-se considerar o uso de testes sorológicos e suas limitações. No desenvolvimento de um programa de estabelecimento de propriedades livres, a PCR poderá permitir a detecção de animais infectados nos quais a sorologia não seja conclusiva.

\section{REFERÊNCIAS BIBLIOGRÁFICAS}

ADAMS, D.S., OLIVER, R.E., AMEGHINO, E. et al. Global survey of serological evidence of caprine arthritis-encephalitis virus infection. Vet. Rec., v.115, p.493-495, 1984

ADAMS, D.S., GORHAM, J.R. The gp135 of caprine arthritis encephalitis virus affords greater sensitivity than the p28 in immunodiffusion serology. Res. Vet. Sci., v.40, p.157-160, 1986.

CASTRO, R.S., LEITE, R.C., RESENDE, M. et al. Isolamento e identificação pela imunofluorescência direta e reação em cadeia de polimerase do vírus da artrite-encefalite caprina. Arq. Bras. Med. Vet. Zootec., v.51, p.235-240, 1999.

CORK, L.C., HADLOW, W.J., CRAWFORD, T.B. et al. Infectious leukoencephalomyelitis of young goats. J. Infect. Dis., v.129, p.134-141, 1974.

CRAWFORD, T.B., ADAMS, D.S., CHEEVERS, W.P. Chronic arthritis in goats caused by a retrovirus. Science, v.207, p.997-999, 1980

CUNHA, R.G., NASCIMENTO, M.D. Ocorrência de anticorpos para o vírus da artrite-encefalite caprina em soros de caprinos do Estado do Rio de Janeiro. Rev. Bras. Med. Vet., v.17, p.72-75, 1995.

DICKSON, J., ELLIS, T. Experimental caprine retrovirus infection in sheep. Vet. Rec., v.125, p.649, 1989.

GENDELMAN, H.E., NARAYAN, O., MOLINEAUX, S. et al. Slow persistent replication of lentiviruses: role of tissue macrophages and macrophages precursors in bone marrow. Proc. Natl. Acad. Sci., v.82, p.7086-7090, 1985.

GENDELMAN, H.E., NARAYAN, O., KENNEDY-STOSKOPF, S. et al. Tropism of sheep lentiviruses for monocytes: susceptibility to infection and virus gene expression increase during maturation of monocytes to macrophages. J. Virol., v.58, p.67-74, 1986.

GOGOLEWSKI, R.P., ADAMS, D.S., MCGUIRE, T.C. et al. Antigenic cross-reactivity between caprine arthritisencephalitis, Visna and progressive pneumonia viruses involves all virion-associated proteins and glycoproteins. J. Gen. Virol., v.66, p.1233-1240, 1985.

HÖTZEL, I., BASTOS, E.S., RAVAZZOLO, A.P. et al. Caprine arthritis-encephalitis virus: isolation and identification in Rio Grande do Sul, Brazil. Braz. J. Med. Biol. Res., v.26, p.1175-1179, 1993.

JOAG, S.V., STEPHENS, E.B., NARAYAN, O. Lentiviruses. In: FIELDS, B.N., KNIPE, D.M., HOWLEY, P.M. Virology. New York: Lippincott-Raven, 1996. v.2, Cap.62, p.1977-1996.

KENNEDY-STOSKOPF, S., NARAYAN, O., STRANDBERG, J.D. The mammary gland as a target organ for infection with caprine arthritis-encephalitis virus. J. Comp. Pathol., v.95, p.609-617, 1985.

LECHNER, F., MACHADO, J., BERTONI, G. et al. Caprine arthritis encephalitis virus dysregulates the expression of cytokines in macrophages. J. Virol., v.71, p.7488-7497, 1997.

LEGASTELOIS, I., COTTIN, V., MORNEX, J.F. et al. Alveolar macrophages from sheep naturally infected by visna-maedi virus contribute to IL-8 production in the lung. Vet. Immunol. Immunopathol., v.59, p.131-139, 1997.

LEROUX, C., VUILLERMOZ, S., MORNEX, J.F. et al. Genomic heterogeneity in the pol region of ovine lentiviruses obtained from bronchoalveolar cells of infected sheep from France. J. Gen. Virol., v.76, p.1533-1537, 1995.

MARCHESIN, D.M. Caracterização molecular de parte do gene gag dos lentivírus artrite-encefalite caprina (CAEV) e Maedi-Visna dos ovinos (MVV), isolados de animais naturalmente infectados do Rio Grande do Sul, Brasil. Porto Alegre: Universidade Federal do Rio Grande do Sul, 1997. 111p. (Tese, Mestrado).

MARCHESIN, D.M., MOOJEN, V., RAVAZZOLO, A.P. Caracterização molecular parcial do gene gag de amostras do vírus da artrite-encefalite caprina (CAEV) isoladas de animais naturalmente infectados no Rio Grande do Sul, Brasil. Pesq. Vet. Bras., v.18, p.119-126, 1998. 
MOOJEN, V., SOARES, H.C., RAVAZZOLO, A.P. et al. Evidência de infecção pelo lentivírus (Maedi-Visna/ArtriteEncefalite Caprina) em caprinos no Rio Grande do Sul, Brasil. Arq. Fac. Vet. UFRGS, v.14, p.77-78, 1986.

NARAYAN, O., CLEMENTS, J.E. Review article. biology and pathogenesis of lentiviruses. J. Gen. Virol., v.70, p.1617$1639,1989$.

NARAYAN, O., JOAG, S.V., CHEBLOUNE, Y. et al. Visna-Maedi: The prototype lentiviral disease. In: NATHANSON, N. Viral Pathogenesis. New York: Lippincott-Raven, 1997. Cap.27, p.657-668.

OAKS, J.L., McGUIRE, T.C., ULIBARRI, C. et al. Equine infectious anemia virus is found in tissue macrophages during subclinical infection. J. Virol., v.72, p.7263-7269, 1998.

RIMSTAD, E., EAST, N.E., TORTEN, M. et al. Delayed seroconversion following naturally acquired caprine arthritisencephalitis virus infection in goats. Am. J. Vet. Res., v.54, p.1858-1862, 1993.

SALTARELLI, M., QUERAT, G., KONINGS, D.A.M. et al. Nucleotide sequence and transcriptional analysis of molecular clones of CAEV which generate infectious virus. Virology, v.179, p.347-364, 1990.

TURELLI, P., GUIGUEN, F., MORNEX, J.F. et al. dUTPase-minus caprine-arthritis virus is attenuated for pathogenesis and accumulates G-to-A substitutions. J. Virol., v.71, p.4522-2530, 1997.

ZANONI, R.G., NAUTA, I.M., KUHNERT, P. et al. Genomic heterogeneity of small

ruminant lentiviruses detected by PCR. Vet. Microbiol., v.33, p.341-351, 1992. 